\title{
IMPLEMENTASI IDENTIFIKASI SISTEM METODE BLACK BOX PADA MOTOR DC MENGGUNAKAN CORRELATION ANALYSIS DAN MODEL ARX
}

\author{
Fakhruddin Mangkusasmito, Dista Yoel Tadeus, Arkhan Subari \\ Program Studi S.Tr Teknik Listrik Industri, Sekolah Vokasi, Universitas Diponegoro \\ J1. Prof. Soedarto, SH, Kampus Undip Tembalang, Semarang, Indonesia 50275
}

\begin{abstract}
The identification system is a procedure to obtain a model of a system, then of the model will be validated to see the accuracy of the model is obtained, compared to the input-output results obtained from the experiments. In the identification system itself known two methods, the method of "non-parametric" and "parametric". On the other hand, DC motor is a type of motor that uses direct electric current to produce rotational mechanical energy and is widely used in various applications. In this study, input and output data acquisition will be performed on the Feedback brand DC motor, and the data will be processed so that the system model is obtained by the black box method. The data will then be processed with the help of MATLAB software. The input signal used in this experiment is Pseudorandom binary sequence (PRBS), which is used because it has a wide frequency range. The signal is generated by an arduino uno microcontroller. From the test results it was found that the validation of the non parametric system model with the correlation analysis method has a fitness value of $=83.19 \%$, while the validation of the parametric system model with the least square ARX method has a fitness value of $=80.59 \%$.
\end{abstract}

Keywords: Identification System; DC Motor; PRBS; correlation analyisis; ARX Model, MATLAB

\section{PENDAHULUAN}

Identifikasi sistem adalah suatu prosedur untuk mendapatkan model dari suatu sistem, kemudian dari model tersebut akan dilakukan validasi untuk melihat ketepatan model yang didapat, dibandingkan dengan hasil input-output yang didapat dari eksperimen. Dalam identifikasi sistem itu sendiri dikenal dua metode, yaitu metode "non parametric" dan "parametric" $[1,2]$. Metode lain yang digunakan untuk mendapatkan sebuah model dari sistem adalah melalui pendekatan analisis dari elemen-elemen pada suatu sistem dengan menggunakan hukum-hukum fisika (seperti: Hukum Newton, Hukum Kirchoff, dll) [3]. Kelemahan dari metode ini adalah banyak dilakukan linierisasi dari karakteristik sistem, sehingga dapat mengurangi ketepatan dari suatu model. Selain itu, kompleksitas suatu sistem akan membuat pemodelan sistem semakin rumit, disamping biasanya tejadi ketidaktersediaan data mengenai parameter-parameter sistem, yang akan makin mempersulit pemodelan sistem [4]. Model sistem yang didapat melalui pendekatan analisis sering disebut sebagi white box model, dan model sistem yang didapatkan dengan pendekatan eksperimen disebut sebagai black box model, sedangkan model yang diperoleh dengan mengkombinasikan keduanya disebut sebagai grey box model. Kelebihan dari pemodelan dengan metode black box adalah sistem fisik yang akan dimodelkan dianggap sebagai sebuah black box sehingga jenis maupun bahan dari komponen sistem didalamnya tidak perlu diperhatikan[5]. Terdapat beberapa struktur model yang didapat melalui metode eksperimen ini antara lain ARX Model[6], RBF-ARX model [7] yang bersifat parametric, dan Correlation analysis[8], yang bersifat non parametric. Algoritma yang digunakan dalam struktur model berbasis eksperimen salah satunya adalah metode least square estimation [9].

Motor adalah mesin yang berfungsi untuk mengubah energi listrik menjadi gerakan mekanik rotasional. Hampir setiap pergerakan mekanik dilakukan oleh motor, termasuk berbagai aplikasi yang ada di industri, motor tersedia dalam berbagai dimensi sesuai dengan kebutuhan spesifikasi gerakan, berdasarkan sumber energinya motor dapat diklasifikasikan menjadi dua yaitu, motor AC dan motor DC. Motor DC merupakan salah satu jenis motor yang menggunakan energi listrik arus searah untuk kemudian diubah menjadi gerakan rotasional. [10].Aplikasi motor DC juga cukup luas, seiring dengan perkembangan salah satu varian dari motor DC yang sering dipakai adalah brushless dc motor atau yang sering disebut motor BLDC. Proses kerja motor BLDC yang bergantian tersebut membuat pemodelan motor BLDC dapat didekati seperti pemodelan motor DC [11]. Penelitian mengenai pemodelan sistem BLDC juga telah banyak dilakukan dan umumnya menggunakan metode analisis atau pemodelan matematis seperti pada [12]-[15], dan dikembangkan pula pemodelan BLDC melalui pendekatan komputasi sistem cerdas seperti artificial neural network[16,17]. Pada penelitian ini akan dilakukan pemodelan sistem pada sebuah plant motor DC dengan metode eksperimen dengan memberikan sinyal input dan menagkuisisi hasil keluarannya sehingga didapat model non parametric dalam bentuk correlation analysis dan model parametric. 


\section{METODOLOGI \\ Desain Eksperimen}

Penelitian ini dilakukan dengan merangkai komponen yang dibutuhkan sehingga dapat dihasilkan sinyal output yang dibutuhkan. Eksperimen untuk pengambilan data mengacu pada diagram percobaan yang diperlihatkan oleh Gambar 1 .

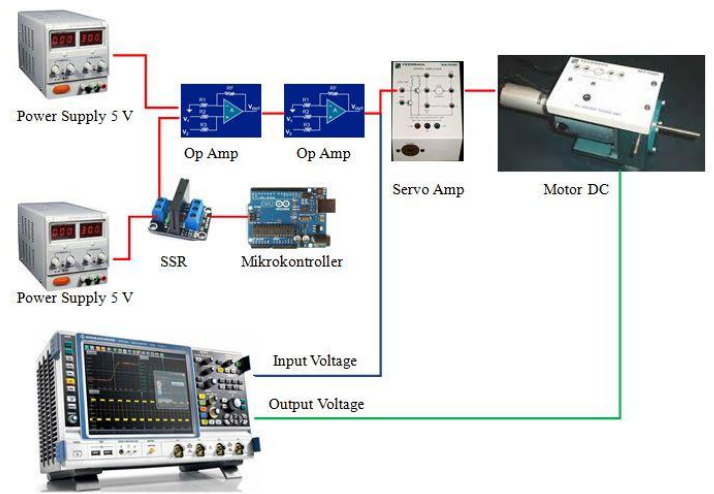

Gambar 1. Skema Eksperimen Pengambilan Data

Adapun fungsi dari masing-masing komponen yang digunakan pada skema di Gambar 1. adalah sebagai berikut:

- Mikrokontroller Arduino Uno

Digunakan untuk menghasilkan sinyal uji (sinyal input pada plant)

- $\quad$ Solid State Relay (Omron G3MB-202P)

Relay digunakan untuk mengatur tegangan yang masuk dari power supply ke summing op-amp.

- Power Supply

Sebagai sumber tegangan, pada eksperimen ini digunakan 2 power supply, masing-masing mensuplai tegangan sebesar $5 \mathrm{Vdc}$

- $\quad$ Summing Op-Amp

Sebagai penjumlah tegangan input yang diberikan pada motor DC,digunakan 2 Inverting Sum Op-Amp untuk membuat tegangan menjadi non inverting, dikarenakan ketersediaan alat eksperimen.

- Servo Amplifier

Sebagai rangkaian driver motor DC, untuk mengatur arah putaran motor.

- Motor DC Feedback

Sebagai sistem "black box" yang akan diidentifikasi, motor DC dengan tegangan maksimal $15 \mathrm{Vdc}$, motor dikopel dengan tachometer sehingga dapat dilihat tegangan keluarannya, motor DC yang digunakan pada penelitian ini merupakan produksi Feedback.

- Osiloskop

Osiloskop digunakan untuk mengetahui input dan output motor DC. Data pembacaan osiloskop terkonversi menjadi data ASCII, sehingga dapat dibaca dalam bentuk angka yang disimpan dalam format .csv.
Rangkaian identifikasi sistem motor DC yang dilakukan diperlihatkan oleh Gambar 2.

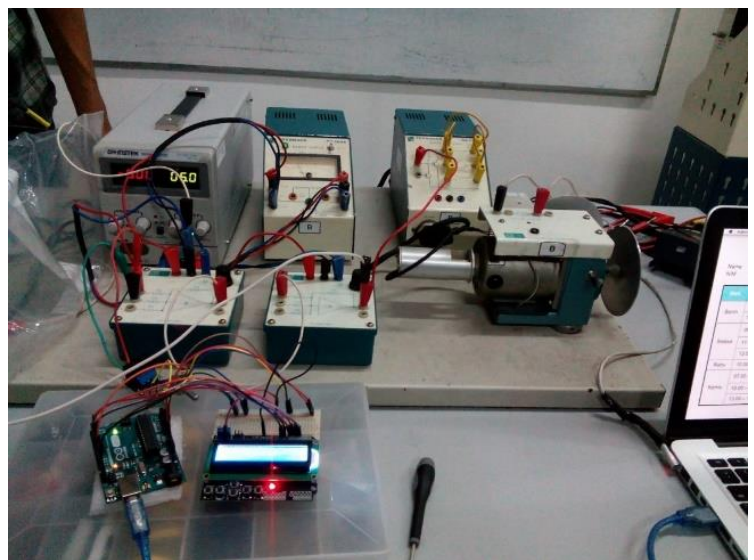

Gambar 2. Rangkaian pengujian identifikasi sistem motor DC

Keluaran dari sistem motor DC tersebut berupa kecepatan sudut dengan satuan putaran per menit (rpm) yang direpresentasikan dalam bentuk tegangan keluaran tachometer yang telah dikopel dengan poros motor DC. Selanjutnya akusisi data input dan output dilakukan dengan osiloskop, untuk selanjutnya data yang dihasilkan dianalisis dengan bantuan software MATLAB.

\section{Algoritma Pengambilan Data}

Pada eksperimen yang dilakukan dalam penelitian ini, dipilih sinyal white noise sebagai sinyal input pada sistem. Dipilih sinyal ini karena karakteristiknya yang memilikki kerapatan spektral daya yang merata pada seluruh komponen frekuensinya, sehingga diharapkan akan mewakili seluruh sinyal input yang mungkin terjadi secara merata dalam proses eksperimen. Pada eksperimen diberikan sinyal Pseudorandom binary sequence (PRBS) untuk merepresentasikan sinyal white noise[17], tegangan yang digunakan ialah $5 \mathrm{Vdc}-$ $10 \mathrm{Vdc}$ sebagai area kerja pada motor yang akan diidentifikasi. Sinyal PRBS akan menghasilkan output berupa sinyal HIGH (1) dan LOW (0) secara terus menerus dan bergantian, dengan lebar sinyal mengikuti periode dari clock. Tegangan $5 \mathrm{Vdc}$ akan menjadi kondisi (0) dan $10 \mathrm{Vdc}$ menjadi kondisi (1) pada sinyal PRBS tersebut. Diagram state dari sinyal PRBS diperlihatkan oleh Gambar 2.

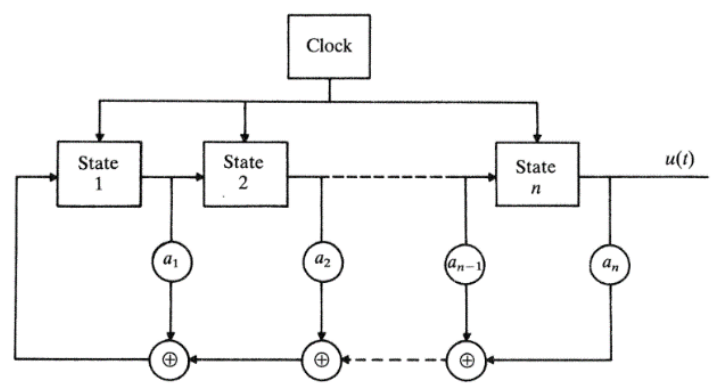

Gambar 2. Diagram state PRBS 
Algoritma untuk menghasilkan sinyal input dalam bentuk tegangan 5-10 Vdc, diperlihatkan oleh Gambar 3 .

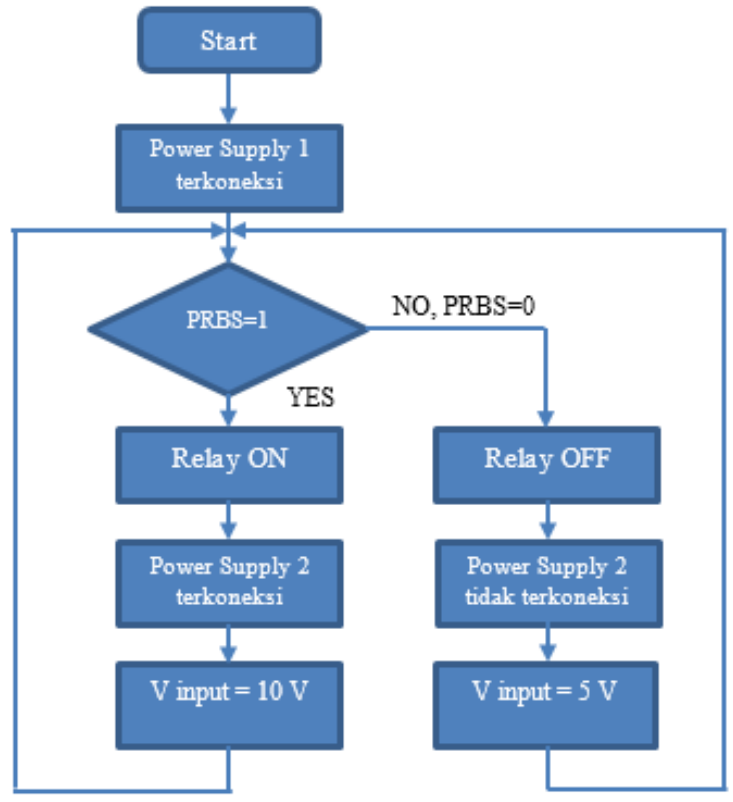

Gambar 3. Algoritma sinyal input motor DC

Untuk menghasilkan sinyal PRBS digunakan program arduino sebagai berikut

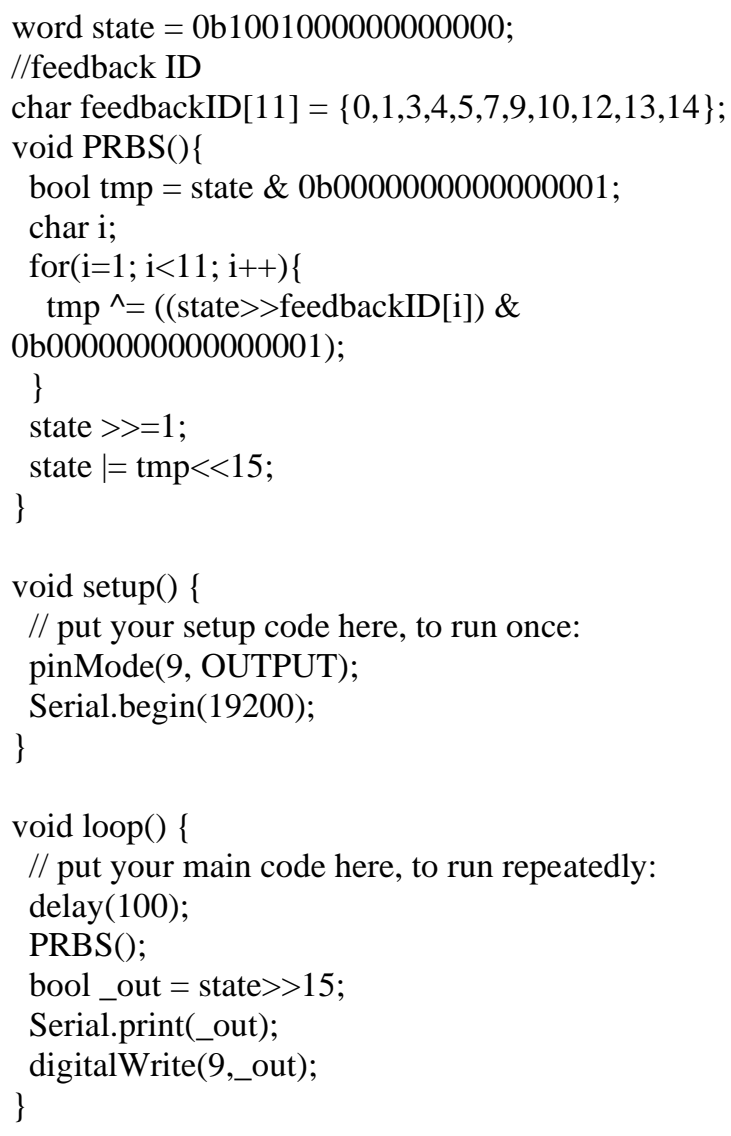

Dari eksekusi program tersebut didapat sinyal PRBS yang ditunjukkan melalui osiloskop. Sinyal tersebut diperlihatkan pada Gambar 4.

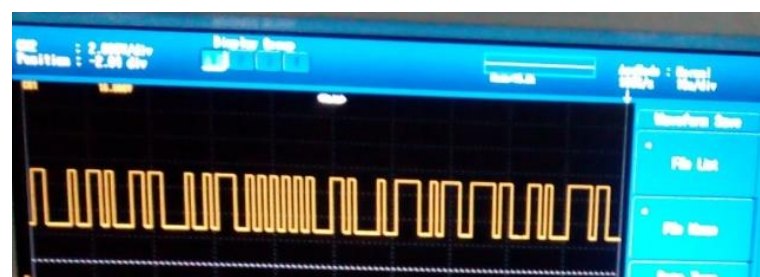

Gambar 4. Sinyal PRBS

\section{Struktur Model}

Untuk melaksanakan proses identifikasi sistem, diperlukan langkah-langkah sebagai berikut:

- Pengambilan data input-output

- Menetukan struktur model

- Estimasi parameter

- Validasi model

Pada penelitian ini, hasil dari akuisis data akan digunakan untuk mendapatkan model sistem dengan metode correlation analysis sebagai metode "non parametric" dan untuk metode "parametric" akan dibangun sebuah model ARX dengan metode least square [1].

\section{a. Correlation Analysis}

Correlation Analysis pada dasarnya adalah metode yang mestimasi respon sistem terhadap masukkan impuls pada sebuah model linier tanpa memperhitungkan secara spesifik orde dari sistem. Bentuk umum pada sistem kontinyu ditunjukkan oleh persamaan berikut

$y(t)=\int_{-\sim}^{t} g(\tau) u(t-\tau) d t$

Sedangkan untuk sistem diskrit ditunjukkan oleh persamaan

$y(t)=\sum_{k=1}^{\tilde{N}} g(k) u(t-k)$

Respon impuls $g(k)$ adalah output sistem dengan input berupa sinyal impuls. Output respon terhadap input umum $u(t)$, didapat dari hasil konvolusi dengan respon impuls.

b. Model ARX

Struktur model ARX ditunjukkan oleh persamaan berikut,

$y(t)+a_{1} y(t-1)+\ldots+a_{n a} y(t-n a)=b_{1} u(t-n k)+\ldots+b_{n b} u(t$

$-n b-n k+1)+e(t)$

Keterangan :

$y(t) \quad$ : Keluaran pada saat waktu $\mathrm{t}$

na : Nilai Poles

$n b \quad$ : Nilai zeroes ditambah 1

$n k \quad$ : Nilai sampel masukkan yang terjadi sesaat sebelum mempengaruhi output disebut dead time

$y(t-1) \ldots y(t-n a)$ : Nilai keluaran sebelumnya $u(t-n k) \ldots u(t-n k-n b+1)$ : Nilai masukkan sebelumnya dan tertunda 
$e(t-1) \ldots e(t-n c):$ Nilai gangguan White-noise

\section{HASIL DAN PEMBAHASAN \\ Data Input-Output Sistem}

Pada penelitian ini dilakukan eksperimen dengan merubah time sampling (ts) pada program arduino, yang bertujuan untuk melihat variasi sinyal input-output yang dihasilkan, sedangkan osiloskop yang digunakan mampu mencuplik 100 sampel setiap detik. Data sinyal input-output dan variasi time sampling yang dilakukan diperlihatkan pada Tabel 1 berikut

Tabel 1. Data Input-Output Eksperimen

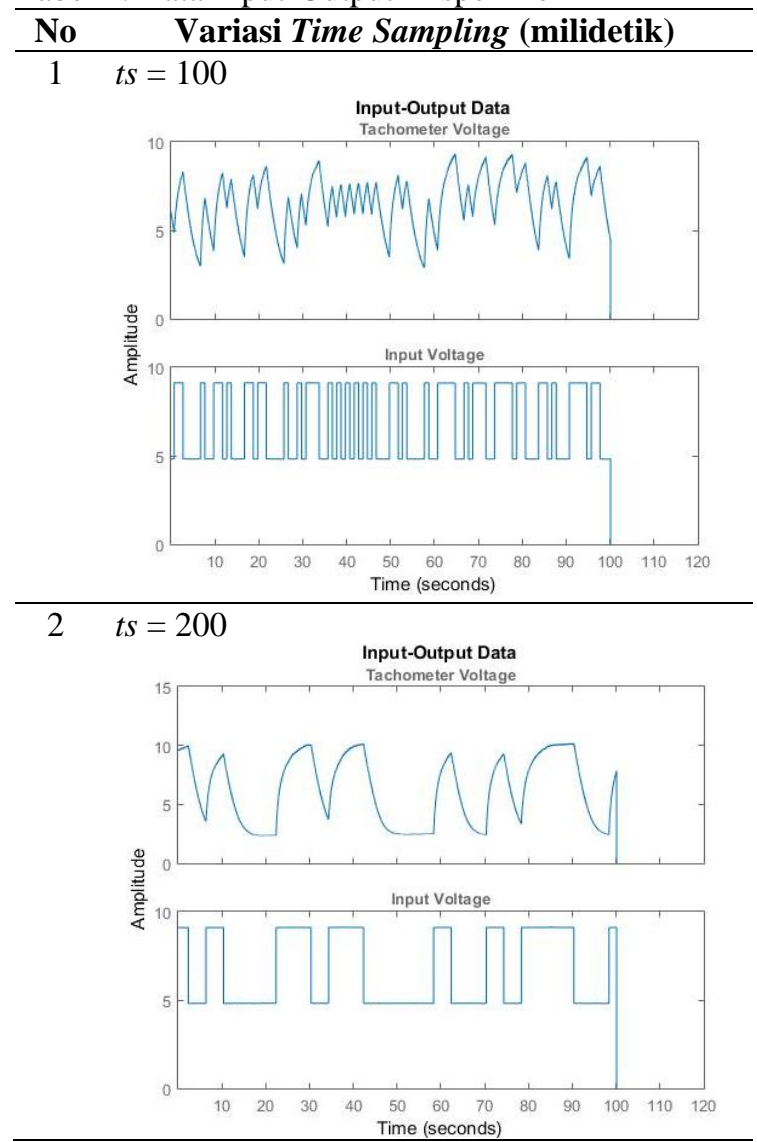

Dari Tabel 1. terlihat bahwa variasi sinyal input PRBS dapat dilakukan dengan mengubah parameter $t s$ pada program arduino, yang akan menghasilkan sinyal output yang berbeda pada sistem. Pengambilan data dilakukan selama 100 detik. Data tersebut nantinya dibagi menjadi 2 bagian yang akan digunakan untuk melakukan proses identifikasi sistem dan bagian lain digunakan untuk validasi model.

\section{Proses Identifikasi}

Pada proses identifikasi, data mentah yang digunakan adalah data pada percobaan 1 seperti yang diperlihatkan oleh Tabel 1, pengolahan data dilakukan dengan software MATLAB. Setelah mengimpor data tersebut ke workspace MATLAB, dibuat obyek "iddata" yang menyatakan data ch2_6 sebagai output, dan data ch1_6 sebagai input. Didefinisikan pula time sampling pengambilan data eksperimen sebesar 1/100, dan juga digunakan fungsi MATLAB "dtrend" yang bertujuan untuk menghilangkan tren dan fungsi yang tidak terpakai. Data yang akan digunakan untuk proses identifikasi adalah data ke 1000 hingga 4000 dari data mentah percobaan 1, sebagai berikut:

z1 = iddata(ch2_6,ch1_6,1/100);

ze_1 = dtrend(z1(1000:4000));

figure

plot(ze_1)

Dari script tersebut diperoleh data baru yang akan diproses lebih lanjut, yang diperlihatkan oleh Gambar 4.

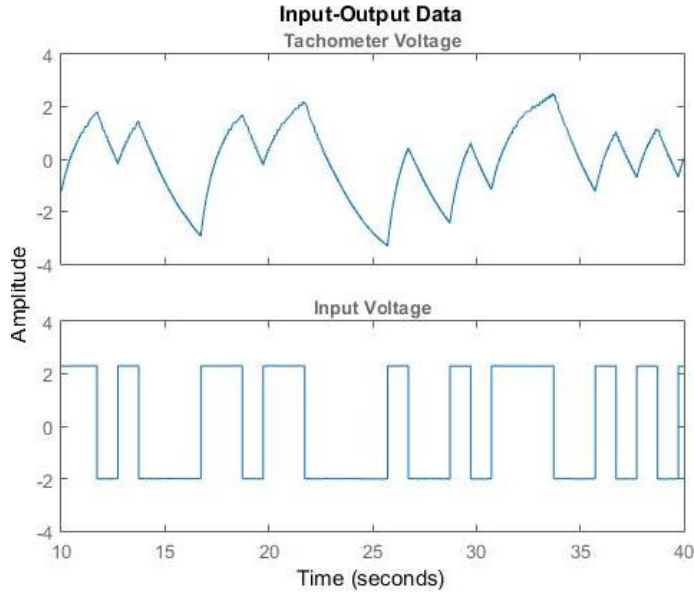

Gambar 4. Data Input-Output untuk identifikasi sistem

Selanjutnya data tersebut diproses sesuai struktur model yang dibahas pada bab sebelumnya, yaitu Correlation Analysis dan Model ARX.

\section{a. Correlation Analysis}

Untuk mendapatkan model non parametric melalui correlation analysis dapat dilakukan dengan menggunakan script MATLAB sebagai berikut :

\% Nonparametric Modeling: Correlation Analysis Impulse Response model

$\mathrm{CA}=$ impulseest(ze_1);

Dari script yang diberikan di atas akan diperoleh hasil sebagai berikut :

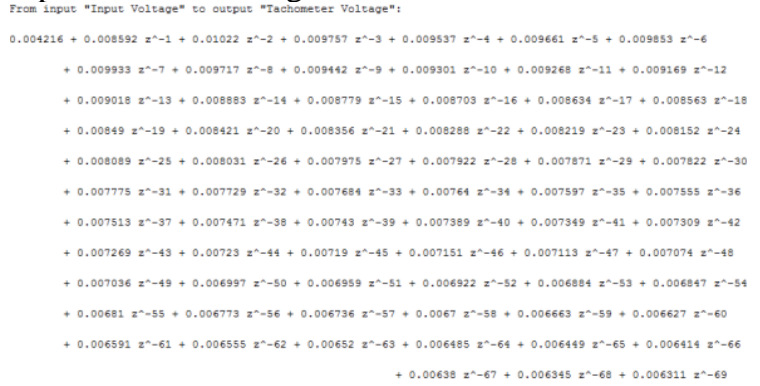

Status:

Estimated using IMPULSEEST on time domain data "ze_1" 
Fit to estimation data: $31.35 \%$

FPE: 0.8991, MSE: 0.8585

Dari hasil perhitungan dengan correaltion analysis secara default, model yang didapat memilikki nilai fitness terhadap data estimasi hanya $31.35 \%$. Pada help matlab terdapat keterangan bahwa, fungsi "impulseest" dapat diset nilai orde yang diinginkan untuk itu, dilakukan pengujian dengan menaikkan orde fungsi, dan didapat hasil fitness yang diperlihatkan oleh Tabel 2.

Tabel 2. Hasil Variasi Orde dan Nilai Fitness Model pada Correlation Analysis

\begin{tabular}{cc}
\hline Jumlah Orde & Nilai Fitness (\%) \\
\hline 70 & 31.35 \\
100 & 41.12 \\
150 & 55.51 \\
200 & 65.3 \\
300 & 77.9 \\
\hline
\end{tabular}

Dari hasil pengujian yang diperlihatkan pada Tabel 2, terlihat bahwa pada pemilihan orde polynomial yang dinaikkan akan menghasilkan nilai fitness model yang semakin baik. Pada pengujian yang dilakukan nilai orde 300 memilikki nilai fitness paling baik.

\section{b. Model ARX}

Untuk mendapatkan model ARX melalui metode least square, dengan nilai $\mathrm{n}_{\mathrm{a}}=2, \mathrm{n}_{\mathrm{b}}=3$ dan $\mathrm{n}_{\mathrm{k}}=2$, digunakan script sebagai berikut

$\%$ Parametric modeling: Least squares - ARX model $\% \mathrm{y}(\mathrm{k})+\mathrm{a} 1 \mathrm{y}(\mathrm{k}-1)+\mathrm{a} 2 \mathrm{y}(\mathrm{k}-2)=\mathrm{b} 1 \mathrm{u}(\mathrm{k}-2)+\mathrm{b} 2 \mathrm{u}(\mathrm{k}-$ 3) + b3 u(k-4)

$\mathrm{ARX}=\operatorname{arx}\left(\mathrm{ze} \_1,\left[\begin{array}{lll}2 & 3 & 2\end{array}\right]\right)$;

Dari script tersebut akan diperoleh model sebagai berikut :

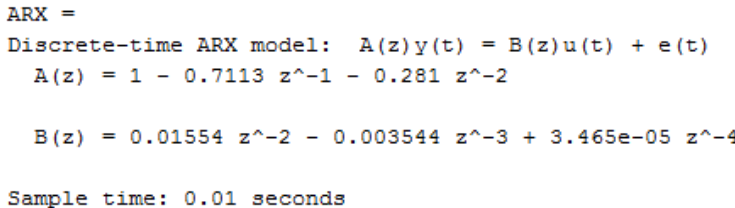

Status:

Estimated using ARX on time domain data "ze_1". Fit to estimation data: $97.34 \%$ (prediction focus) FPE: 0.001288, MSE: 0.001285

Hasil pengujian dengan model ARX didapatkan nilai fitness sebesar 97,34\%.

\section{Respon Model Terhadap Masukan Step}

Dari kedua model yang diperoleh kita juga dapat membandingkan keluaran sistem terhadap sinya step, secara umum respon sebuah plant motor DC terhadap sinyal step haruslah stabil, dan mirip dengan karakteristik sistem orde 1. Dengan menggunakan fungsi MATLAB diperoleh perbandingan respon keduanya yang diperlihatkan oleh Gambar 5.

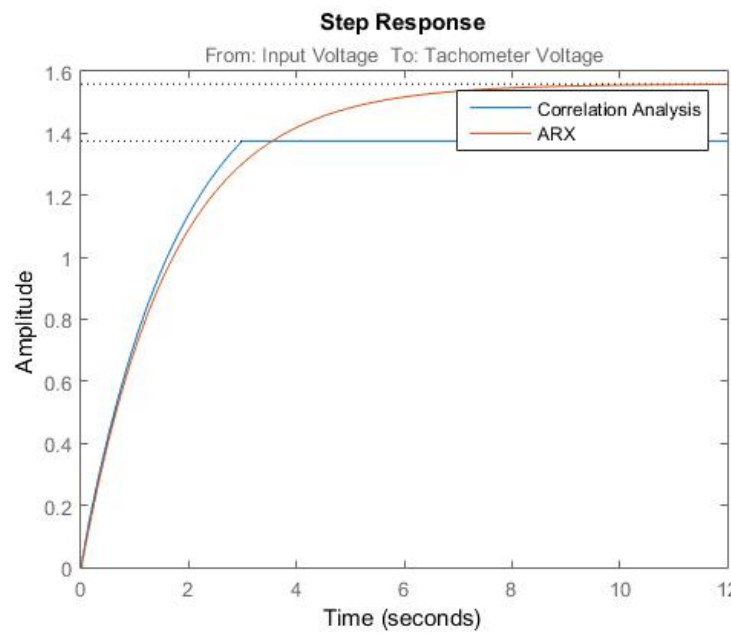

Gambar 5. Perbandingan model ARX dan Correlation Analysis terhadap masukan step

Dari grafik pada Gambar 5. terlihat bahwa terhadap masukan step, model dari correlation analysis memilikki respon transien yang lebih baik ditinjau dari rise time dan settling time yang terlihat lebih cepat dari ARX Model. Kedua model samasama tidak mengalami overshoot terhadap masukan step, dan kedua model sama-sama bersifat stabil.

\section{Validasi Model}

Untuk menguji model yang didapat dari metode Correlation Analysis dan ARX model maka perlu dilakukan validasi dengan menggunakan inputoutput dari data yang tidak digunakan pada proses identifikasi, dalam hal ini akan digunakan data percobaan 1 dari data 5000 hingga 6000, validasi model dilakukan melalui script sebagai berikut

$\%$ Validating the Estimated Model to Experimental Output

$\mathrm{zV}=\operatorname{dtrend}(\mathrm{z} 1(5000: 6000)) ; \%$ preprocess the

validation data

figure compare(zv,CA,ARX);

Dari sript tersebut dihasilkan grafik dan nilai fitness model yang diperlihatkan oleh Gambar 6.

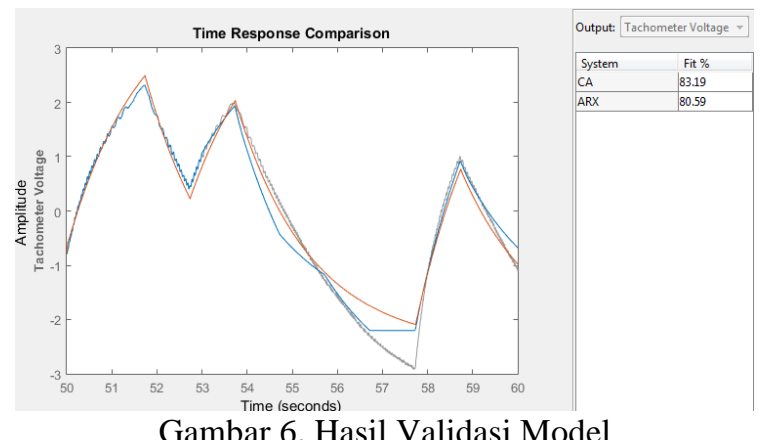

Gambar 6. Hasil Validasi Model 
Dari hasil validasi terlihat bahwa nilai fitness model yang didapat terhadap data validasi relatif baik, di atas $80 \%$, bahkan pada validasi model correlation analysis, nilai fitness yang diperoleh lebih baik terhadap data validasi dibandingkan terhadapt data yang digunakan untuk estimasi model

\section{ANALISIS DAN KESIMPULAN}

Dari eksperimen yang dilakukan pada penelitian ini dapat diperoleh beberapa kesimpulan. Identifikasi "non parametric" dengan metode correlation analysis menghasilkan model berbentuk polynomial, yang memilikki orde tinggi, sehingga model tersebut lebih sesuai bila digunakan untuk validasi data, dibandingkan dengan model least square ARX yang hanya berorde 2. Selain itu metode correlation analysis akan memberikan model yang semakin akurat bila orde polynomial semakin tinggi, sehingga sulit untuk digunakan sebagai bahan analisis lebih lanjut karena kompleksitas dari model yang diperoleh. Sistem motor DC memilikki respon yang stabil terhadap masukan step baik pada model parametric maupun non parametric dengan karakteristik sistem seperti pada sistem orde 1. Untuk identifikasi sistem dengan metode correlation analysis dengan orde 300 didapat nilai fitness $77.9 \%$, sedangkan identifikasi sistem dengan model ARX dengan nilai $\mathrm{n}_{\mathrm{a}}=2, \mathrm{n}_{\mathrm{b}}=3$ dan $\mathrm{n}_{\mathrm{k}}=2$ mendapatkan nilai fitness sebesar $97.34 \%$. Dari hasil validasi model, kedua model yang dihasilkan relatif baik dengan nilai fitness untuk corrrelation analysis $83.19 \%$ dan ARX $80.59 \%$.

\section{DAFTAR PUSTAKA}

1. L. Ljung, 2010, System identification, in The Control Systems Handbook: Control System Advanced Methods, Second Edition.

2. K. J. Keesman, 2011, System identification: An introduction, in Advanced Textbooks in Control and Signal Processing.

3. K. Ogata, 2002, Modern Control Engineering.

4. Nusantoro, G., Muslim, M., \& W., T, 2013, Identifikasi Sistem Plant Suhu dengan Metode Recursive Least Square, Jurnal EECCIS, 6(1), pp. 67-74.

5. M. Ehmer and F. Khan, 2012, A Comparative Study of White Box, Black Box and Grey Box Testing Techniques, Int. J. Adv. Comput. Sci. Appl.

6. P. Potočnik, B. Vidrih, A. Kitanovski, and E. Govekar, 2019, Neural network, ARX, and extreme learning machine models for the shortterm prediction of temperature in buildings, Build. Simul.

7. X. Tian, H. Peng, F. Zhou, and X. Peng, 2019, RBF-ARX model-based fast robust MPC approach to an inverted pendulum, ISA Trans.

8. N. J. Gogtay and U. M. Thatte, 2017, Principles of correlation analysis, J. Assoc. Physicians India.
9. B. Mogharbel, L. Fan, and Z. Miao, 2015, Least squares estimation-based synchronous generator parameter estimation using PMU data, in IEEE Power and Energy Society General Meeting.

10. J. Griffin, 1982, DC motors, Electron. Power.

11. A. Kiruthika, A. A. Rajan, and P. Rajalakshmi, 2013, Mathematical modelling and speed control of a sensored brushless DC motor using intelligent controller, in 2013 IEEE International Conference on Emerging Trends in Computing, Communication and Nanotechnology, ICE-CCN 2013.

12. D. L. Gabriel, J. Meyer, and F. Du Plessis, 2011, Brushless DC motor characterisation and selection for a fixed wing UAV, in IEEE AFRICON Conference.

13. H. K. Samitha Ransara and U. K. Madawala, 2013, Modelling and analysis of a low cost Brushless DC motor drive, in Proceedings of the IEEE International Conference on Industrial Technology.

14. S.Rambabu, Modeling And Control Of A Brushless Dc Motor, 207AD.

15. S. Sdudhe and A. G. Thosar, 2014, Mathematical Modelling And Simulation Of Three Phase Bldc Motor Using Matlab/Simulink.

16. M. Nizam, A. Mujianto, H. Triwaloyo, and Inayati, 2013, Modelling on BLDC motor performance using artificial neural network (ANN), in Proceedings of the 2013 Joint International Conference on Rural Information and Communication Technology and ElectricVehicle Technology, rICT and ICEV-T 2013.

17. I. Colak, M. Sahin, and Z. Esen, 2013, Artificial neural networks controller algorithm developed for a Brushless DC Motor, in Proceedings - 2013 12th International Conference on Machine Learning and Applications, ICMLA 2013.

18. F. Alonge, R. Rabbeni, M. Pucci, and G. Vitale, 2015, Identification and Robust Control of a Quadratic DC/DC Boost Converter by Hammerstein Model, IEEE Trans. Ind. Appl. 